\title{
Synergism effect of rosemary essential oil and some antibiotic against Escherichia coli isolated from clinical samples
}

\author{
Ghusoon A. Abdulhasan \\ Department of Biology, College of Science, University of Baghdad, Baghdad, Iraq
}

\begin{abstract}
Urinary tract infections (UTI) are among the most common infections in humans worldwide, E. coli strains in particular are responsible for $80 \%$ of the UTI cases. Therefore, the study aimed to investigate the antimicrobial activity of Rosemary essential oil (EO) and three most antibiotics used for UTI treatment as well as determine the best combinations between the EO and these antibiotics against E. coli isolated from urine samples. The ability to form biofilm formation was performed and antimicrobial activity for antibiotics and rosemary EO were investigated by minimal inhibitory concentration $(M I C)$ in broth microdilution method. The results showed that all isolates had the ability to produce biofilm (100\%). The MIC value of gentamicin, trimethoprim/sulfamethoxazole, ciprofloxacin and Rosemary EO against E.coli were 256, 2000, 500 and $10^{4}$ $\mu \mathrm{g} / \mathrm{ml}$, respectively for strong biofilm producer isolates while the MIC values were 512, 2000, 1000 and $10^{4}$ $\mu \mathrm{g} / \mathrm{ml}$, respectively for moderate biofilm producer isolates. Combination of gentamicin and ciprofloxacin with $E O$ were reduced the MIC of antibiotics when used alone in both strong and moderate biofilm producer isolates. In conclusion, the combination of gentamicin and ciprofloxacin with rosemary EO were increased the antimicrobial activity of these antibiotics (synergetic effect) against $E$. coli isolated from urine.
\end{abstract}

Keywords: E. coli, gentamicin, ciprofloxacin, Rosemary essential oil, synergism.

\section{Introduction}

Urinary tract infections (UTI) are among the most common infections in humans and is estimated 150 million urinary tract infections per year worldwide [1]. UTI is a bacterial infection can effected any section of urinary tract. The most common cause of it is Gram negative bacteria, especially E. coli that represent the predominant uropathogen responsible for $80 \%$ of UTI [2].

Uropathogenic strains of $E$. coli are characterized by the expression of distinctive bacterial properties, products, or structures which help the organism overcome host defenses and colonize or invade the urinary tract such as adhesions, aerobactin system, hemolysin, $\mathrm{K}$ capsule, and resistance to serum killing [3].

According to the Infectious Diseases Society of America (IDSA) guidelines, Trimethoprim/ sulphamethoxazole is the recommended drug for the treatment of UTIs when the resistance is less than $10-20 \%$ and ciprofloxacin is recommended when the resistance is greater than $20 \%$. Other agents can be used for treatment of UTI include fluoroquinolones, nitrofurantoin, cephalosporins and another $\beta$-lactams with or without $\beta$-lactamase inhibitor [4]. Extended-spectrum b-lactamase (ESBL) produced by E. coli reduces the number of therapeutic options for the infection caused by this pathogen. It is resistant to penicillins, cephalosporins and monobactams and can also develop coresistance to other classes of antimicrobial agents, such as fluoroquinolones, co-trimoxazole, and aminoglycosides, which are frequently used for UTI [5].

The increasing of microorganism's resistance to traditional chemicals and drugs has encouraged scientists to search for novel sources of biocides with broad-spectrum activities. Essential Oils (EOs) are natural products with strong smells that are produced by aromatic plants as secondary metabolites [6], can inhibit or slow the growth of bacteria, yeasts and moulds. The EOs and their components have different targets, specially the membrane and cytoplasm, and in some situations, they completely alter the morphology of the cells. The EOs of Rosemary (Rosmarinus officinalis L.) is also able to inhibit quorum sensing that can regulate a number of activities, such as virulence factor expression, bioluminescence, sporulation, biofilm formation and mating [7].Antimicrobial combinations are used to evaluate the synergistic activity against resistant strains, overcome bacterial tolerance, prevent the emergence of drug resistance, reduce toxicity, and prevent inactivation of an antimicrobial agent by enzymes produced by other bacteria [8].

This study aimed to investigate the antimicrobial activity of Rosemary EO and three most antibiotics used for UTI treatment as well as determine the best combinations between the EO and these antibiotics against $E$. coli isolated from urine samples.

\section{Materials And Methods}

Eight isolates of $E$. coli were isolated from urine using MacCongy agar at $37^{\circ} \mathrm{C}$. All isolates were confirmed using API-20E test kit (Bio-Mereix, France) according to the manufacture instructions in central health laboratory. 


\subsection{Preparation of Essential Oil of $R$. officinalis}

The EO of $R$. officinalis was isolated from air dried leaves $(250 \mathrm{~g})$ by Cleavenger hydrodistillation method. The plant material with D.W (1.2L) was boiled for $3 \mathrm{~h}$, the EO was kept at $4^{\circ} \mathrm{C}$ until use $[9,10]$.

\subsection{Biofilm formation assay}

Biofilm was performed in 96 well microtiter plate as described by ElFartas-Aissani et al. [11] with some modification. Briefly, E. coli isolates were subcultured in nutrient broth over night at $37^{\circ} \mathrm{C} .200 \mu \mathrm{l}$ of bacterial cultures $\left(O D_{540} 0.64=10^{8} \mathrm{cell} / \mathrm{ml}\right)$ were transferred to each well in triplicate and incubated $24 \mathrm{~h}$ at $37^{\circ} \mathrm{C}$ and negative control contain media only. The media was removed and washed three times with PBS then $200 \mu 1$ of crystal violate $(0.1 \% \mathrm{w} / \mathrm{v})$ added to the wells for $15 \mathrm{~min}$ at room temperature. Crystal violate was removed and washed three times with PBS. The crystal violate inside the cells was dissolved by absolute ethanol $(200 \mu \mathrm{l})$ and the absorbance was measured by an ELISA reader. Comparing the O.D of biofilm to the control and according to the reading the isolates were classified as follows: $\mathrm{O} . \mathrm{D} \leq \mathrm{O} . \mathrm{D}_{\mathrm{c}}$ no biofilm producer, $\mathrm{O}_{\mathrm{D}} \mathrm{D}_{\mathrm{c}}<\mathrm{O} . \mathrm{D} \leq 2$ $\times \mathrm{O} \mathrm{D}_{\mathrm{c}}$ weak biofilm, $2 \times \mathrm{O} . \mathrm{D}_{\mathrm{c}}<\mathrm{O} . \mathrm{D} \leq 4 \times \mathrm{O}_{\mathrm{C}} \mathrm{D}_{\mathrm{c}}$ moderate and $4 \times \mathrm{O} . \mathrm{D}_{\mathrm{c}}<\mathrm{O} . \mathrm{D}$ strong biofilm.

\subsection{Determination of minimal inhibitory concentration (MIC)}

The MIC values of gentamicin, trimethoprim/sulfamethoxazole, ciprofloxacin and Rosemary EO were evaluated using microdilution method in 96 well microtiter plate as recommended by the clinical and laboratory standard institute [12]. Gentamicin (40mg/ml), trimethoprim/sulfamethoxazole (80mg), ciprofloxacin $(500 \mathrm{mg})$ were dissolved in diluted $\mathrm{HCl}(0.1 \mathrm{~N})$ and $\mathrm{EO}\left(10^{5} \mu \mathrm{g} / \mathrm{ml}\right)$ dissolving in DMSO were used to prepared two fold serial dilutions with nutrient broth in a final concentration ranging from $16-512 \mu \mathrm{g} / \mathrm{ml}$ for gentamicin, $15-500$ $\mu \mathrm{g} / \mathrm{ml}$ for trimethoprim/sulfamethoxazole, $125-4000 \mu \mathrm{g} / \mathrm{ml}$ for ciprofloxacin and $156-2 \times 10^{4} \mu \mathrm{g} / \mathrm{ml}$ for EO. For synergism effect, the previous mentioned concentrations of antibiotics were mixed with MIC of EO. The bacterial inoculums were added at final concentration $1 \times 10^{6} \mathrm{cell} / \mathrm{ml}$, bacteria and media control were prepared. The results were recorded after incubation at $37^{\circ} \mathrm{C}$ for $18 \mathrm{~h}$ by determining MIC (the lowest concentration of gentamicin and EO that prevents growth of the microorganism). MIC was calculated by take the absorbance of wells that did not skip the value of the absorbance of media control [13].

\subsection{Determination of fractional inhibitory concentration (FIC) index}

The fractional inhibitory concentration index was measured for the combination of gentamicin, trimethoprim/sulfamethoxazole or ciprofloxacin with Rosemary EO using the equation (1):

FIC $=$ MIC drug A / MIC drug A + MIC drug B / MIC drug B in combination alone in combination alone

Drug combinations were classified into synergetic FIC $\leq 0.5$, partial synergetic $0.5<\mathrm{FIC}<1$, additive FICI $=1$, indifferent $1<$ FICI $<4$ and antagonism FICI $\geq 4[14,15]$.

\section{Results And Discussion}

Urinary tract infection is one of the most important causes of morbidity in the general population. Urinary tract infection is an old problem that continues to present new challenges due to change in the manner of causation of UTl and in the antimicrobial susceptibility of urinary pathogens over the years.

According to present study, E. coli have the ability to produce biofilm and the results showed $100 \%$ ( 8 isolates) of isolates produce biofilm and classified as $2(20 \%)$ isolates were strong biofilm producer, $6(64 \%)$ isolates were moderate biofilm producers.

Biofilm formation may even result in the increased ability of strains causing acute prostatitis to persist and lead to the recurrent UTIs. It has been reported that $63 \%$ of $E$. coli strains collected from patients with prostatitis were biofilm producers in contrast to $40 \%$ of $E$. coli strains causing cystitis and pyelonephritis [16]. The MIC value of gentamicin, trimethoprim/sulfamethoxazole, ciprofloxacin and Rosemary EO against E.coli were determined by broth microdilution method. The MIC values were 256, 2000, 500 and $10^{4} \mu \mathrm{g} / \mathrm{ml}$ respectively for strong biofilm producer isolates while the MIC values were 512, 2000, 1000 and $10^{4} \mu \mathrm{g} / \mathrm{ml}$ respectively for moderate biofilm producer isolates.

The most effective antibiotics against $E$. coli isolates were ciprofloxacin, levofloxacin and norfloxacin (susceptibility percent was 96\%) followed by nalidixic acid $92 \%$ and gentamicin $84 \%$. The MIC of ciprofloxacin ranged between $15.6-500 \mu \mathrm{g} / \mathrm{ml}$ while gentamycin was $31.25-500 \mu \mathrm{g} / \mathrm{ml}[1]$.

The MIC results of combinations between antibiotics and EO according to FIC index (table 1) showed synergism effect when used gentamicin and ciprofloxacin with EO (FIC $\leq 0.5)$ against both moderate and strong biofilm isolates as shown in figure 1 and 2 . 


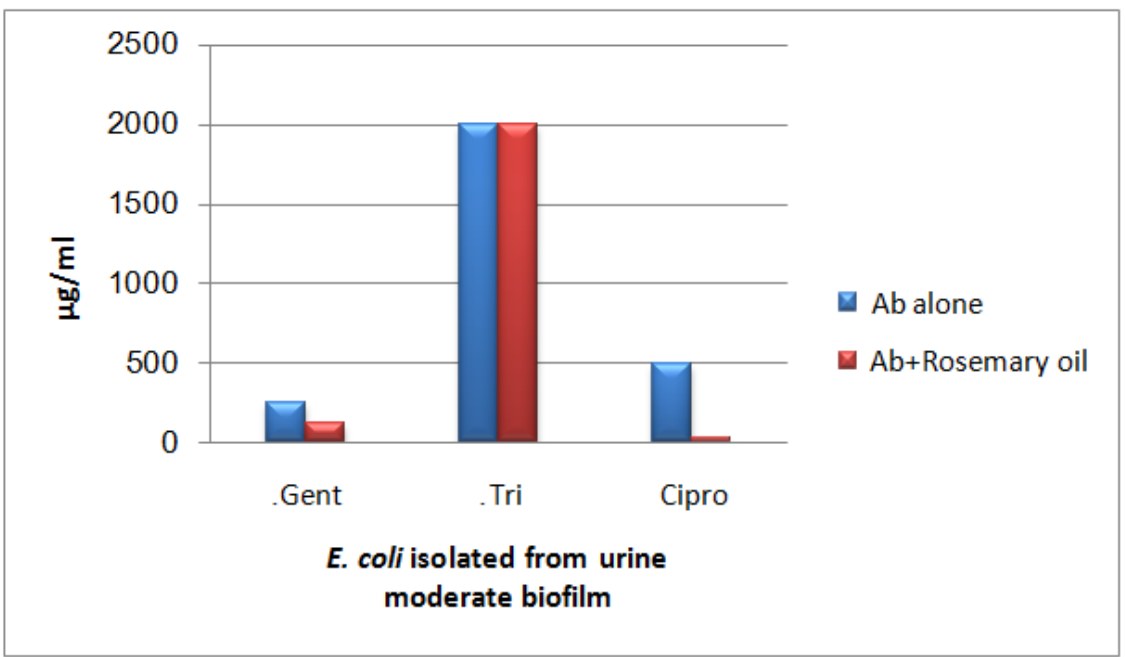

Figure 1. MIC values of antibiotic alone and in combination with rosemary EO against $E$. coli moderate biofilm.

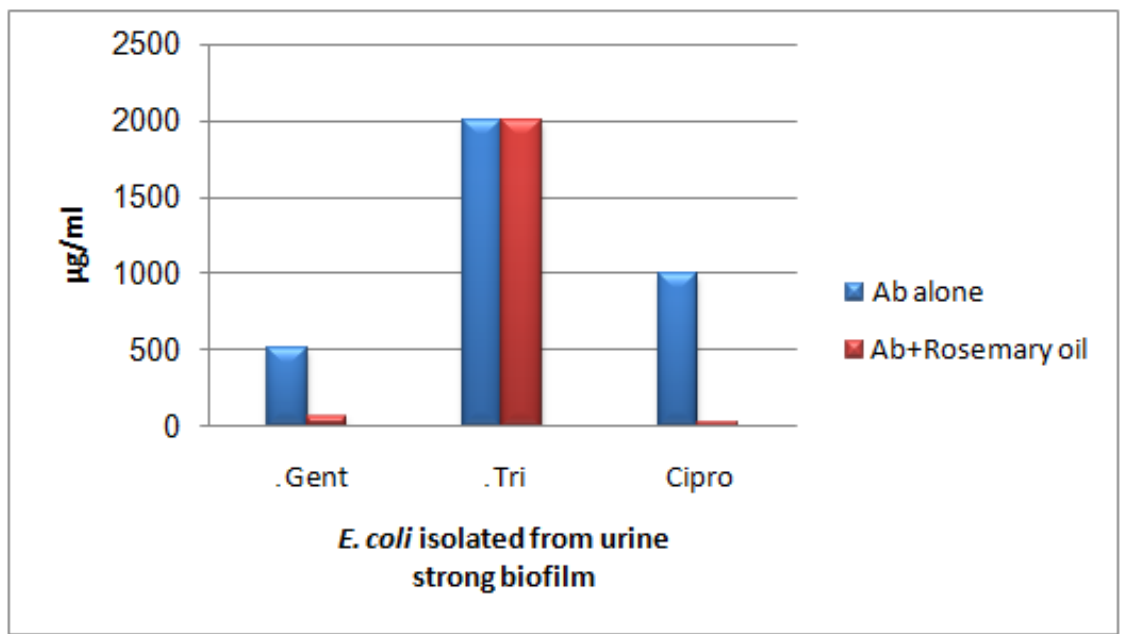

Figure 2. MIC values of antibiotic alone and in combination with rosemary EO against $E$. coli strong biofilm.

In moderate biofilm producer, the combination of gentamicin with EO was reduced the MIC one fold (MIC 128 $\mu \mathrm{g} / \mathrm{ml})$ and approximately sixteen fold $(31 \mu \mathrm{g} / \mathrm{ml})$ in reduction when combination ciprofloxacin with EO.

In comparison with strong biofilm producer, the MIC were reduced 8 fold $(64 \mu \mathrm{g} / \mathrm{ml})$ and 32 fold $(31 \mu \mathrm{g} / \mathrm{ml})$ when combination gentamicin and ciprofloxacin respectively with EO.

Plant could be considered as a source of compounds that increase the sensitivity of bacterial cells to antibiotics [17]. Essential oils and their components targeted the membrane, cytoplasm and other components of the cells [7], therefore, it is possible that rosemary EO increased the permeability of cell to antibiotics that lead to reduced the MIC of gentamicin and ciprofloxacin especially in moderate biofilm.

Table 1. FIC index of antibiotics combinations with Rosemary EO against $E$. coli isolates.

\begin{tabular}{|l|c|c|c|}
\hline \multirow{2}{*}{ Biofilm } & \multicolumn{3}{|c|}{ FIC Index } \\
\cline { 2 - 4 } & Gentamicin & Trimethoprim/sulfamethoxazole & Ciprofloxacin \\
\hline Strong & $\begin{array}{c}0.257 \\
\text { (Synergetic) }\end{array}$ & $\begin{array}{c}1.2 \\
\text { (indifferent) }\end{array}$ & $\begin{array}{c}0.065 \\
\text { (Synergetic) }\end{array}$ \\
\hline Moderate & $\begin{array}{c}0.263 \\
\text { (Synergetic) }\end{array}$ & $\begin{array}{c}1.2 \\
\text { (indifferent) }\end{array}$ & $\begin{array}{c}0.034 \\
\text { (Synergetic) }\end{array}$ \\
\hline
\end{tabular}

All isolates not observed changed in MIC of trimethoprim/sulfamethoxazole when used alone or mixed with EO which might be belonged to resistant of the bacterial cells to this type of antibiotic. Mounchid et al. [6] mentioned the E. coli strain that was resistant to several antibiotics was susceptible to the essential oils of R.officinalis $L$. 
The combination of the aqueous garlic extract and ciprofloxacin which led to the synergism effect on $E$. coli isolates, may be due to increasing the diffusion of this antibiotic to inside of the bacterial cells as the garlic may affect the cell wall of the microorganism [18], also the combination between clove alcoholic extract and antibiotics such as gentamicin, levofloxacin, amikacin and norfloxacin increase the synergistic effect of antibiotics against selected $E$. coli isolates [1]. In another study, Silymarin demonstrated synergistic activity in modulating the effect of aminoglycosides against E. coli reducing the MIC from 312.5 to $156.25 \mu \mathrm{g} / \mathrm{ml}$ for amikacin and from 78.125 to $39.06 \mu \mathrm{g} / \mathrm{mL}$ for gentamicin [19].

\section{Conclusion}

In conclusion, the combination of gentamicin and ciprofloxacin with rosemary EO were increased the antimicrobial activity of these antibiotics (synergetic effect) against $E$. coli isolated from urine.

\section{References}

[1]. O. Al-Jiffri, Z. M.F. El-Sayed, and F. M. Al-Sharif. Urinary Tract Infection with and Antibacterial Activity of Some Plants Extracts. International Journal of Microbiological Research, 2 (1), 2011, 01-07.

[2]. A. Ronald .The Etiology of Urinary Tract Infection: Traditional and Emerging Pathogens. Dis.,49(2),2003, 71-82.

[3]. J. R. Johnson. Virulence Factors in Escherichia coli Urinary Tract Infection. Clin. Microbiol. Rev., 4 (1), 1991, 80-128.

[4]. J. Mandal, N. Srinivas Acharya, D. Buddhapriya, and S. Parija. Antibiotic resistance pattern among common bacterial uropathogens with a special reference to ciprofloxacin resistant Escherichia coli. Indian J. Med. Res., 136(5), $2012,842-849$.

[5]. H. Liu, Lin, Y. Lin, S. Yu, W. Wu and Y. Lee. Antimicrobial Susceptibilities of Urinary Extended Spectrum Beta-lactamase Producing Escherichia coli and Klebsiella pneumoniae to Fosfomycin and Nitrofurantoin in a Teaching Hospital in Taiwan. Journal of Microbiology, Immunology and Infection, 44, 2011, 364-368.

[6]. K. Mounchid,F. Bourjilat, N. Dersi, T. Aboussaouira, A. Rachidai, A. Tantaoui-Elaraki, and M. Alaoui-Ismaili. The susceptibility of Escherichia coli strains to essential oils of Rormarinus officinalis and Eucalyptus globules. African Journal of Biotechnology, 4 (10), 2005, 1175-1176.

[7]. F. Nazzaro, F. Fratianni, L. De Martino, R. Coppola and V. De Feo. Effect of Essential Oils on Pathogenic Bacteria. Pharmaceutic, 6(12), 2003, 1451-1474

[8]. G. Miranda-Novales, B.E. Miranda, M. Vilchis-Pérez and F. Solórzano-Santos. In Vitro Activity Effects of Combinations of Cephalothin, Dicloxacillin, Imipenem, Vancomycin and Amikacin against Methicillin-Resistant Staphylococcus spp. strains. Ann. Clin. Microbiol. Antimicrob., 5, 2006, 25.

[9]. R. Jamshidi, Z. Afzali, and D. Afzali. Chemical Composition of Hydrodistillation Essential Oil of Rosemary in Different Origins in Iran and Comparison with Other Countries. American-Eurasian J. Agric. \& Environ. Sci., 5 (1), 2009, 78-81.

[10]. A.M. Najem, I.J. Abed and A.M. AL-Haidari. Evaluation the Activity of Rosemary (Rosmarinus officinalis L.) Essential Oil against Some Cyanobacteria. Iraqi J Biotechnol, 15, 2016, 97-102.

[11]. R. El Fertas Aissani, Y. Messai, S. Alouache, and R. Bakour. Virulance Profiles and Antibiotics Suscepitibility Patterns of Klebsiella pneumoniae Strains Isolated from Different Clinical Specimens. Pathologie Biologie., 61(5), 2013, $209-216$.

[12]. Clinical and Laboratory Standards Institute (CLSI). Microdilution method. Methods and Dilution Antimicrobial Susuptibility test for Bacteria that Grow Aerobically. Vol 32(2). 9th ed. USA. 2012, pp: 16-18.

[13]. A. Budzynska, M. Wieckowska-Szakiel, B. Sadowska, D. Kalemba, and B. Rozalska

. Antibiofilm Activity of Selected Essential Oils and their Major Components. Polish J. of Microbiology, 60(1), 2011, 35-41.

[14]. H. Ulvatne, S. Karoliussen, T. Stiberg, O. Rekdal, and J.S. Svendsen. Short Antibacterial Peptides and Erythromycin Act Synergically against Escherichia coli. Journal of Antimicrobial Chemotherapy, 48, 2001, 203-208.

[15]. D.M. Johnson, T.R. Fritsche, H.S Sader and R.N. Jones. Evaluation of Dalbavancin in Combination with Nine Antimicrobial Agents to Detect Enhanced or Antagonistic Interaction. Int. J. Antimicrob. Agents, 27, 2006, 557-560.

[16]. S.M. Soto. Importance of Biofilms in Urinary Tract Infections: New Therapeutic Approaches. Advances in Biology, 4, $2014,1-13$.

[17]. T. Sibanda and A. Okoh. The Challenges of Overcoming Antibiotic Resistance: Plant Extracts as Potential Sources of Antimicrobial and Resistance Modifying Agents. African J. Biotechnol.,6, 2007, 2886-2896.

[18]. S.S. Zain al-abdeen, I.T. Abdullah and S.S. Al-Salihi. The Synergism Effect of Aqueous Garlic Extract and Ciprofloxacin against Some Multi-resistant Bacteria. J. Microbiol. Biotech. Res., 3 (3), 2013,136-140.

[19]. D.R. de Oliveira, S.R. Tintino, M.F. Braga, A.A. Boligon, M.L. Athayde, H. Coutinho, I.R.de Menezes and R. Fachinetto. In Vitro Antimicrobial and Modulatory Activity of the Natural Products Silymarin and Silibinin. BioMed Research International, Article ID 292797, 2015, $1-7$. 